\title{
The Virtual Court Action: procedural facilitation in law
}

\author{
Karen Barton* and Patricia McKellar** \\ * Department of Business Administration, Glasgow Caledonian University \\ **Department of Law and Public Administration, Glosgow Caledonian University
}

One of the difficulties of learning procedural law is that students need to understand and memorize the forms of action which can be carried out by parties to a case. The Virtual Court Action allows students to take an active part in their learning by enabling them to carry out simulated court actions. Within the simulation, students are assigned roles, and progress the action, as in court, lodging documents, corresponding by email and meeting time limits when appropriate. Throughout, students draw from a library of style templates, and assemble documents electronically through a series of dialogues which assist them in the drafting process. The Virtual Court Action enhances traditional legal heuristics by allowing students to become part of what they are learning. It fosters a student-centred, problem-solving vocational environment, allows users to progress at their own rate, and supports different learning styles. Above all, it is an example of the use of realia to enable procedural facilitation not only in legal studies, but in CBL as well.

\section{Introduction: teaching and learning procedural law}

When they learn procedural law, students need to understand and memorize the forms of legal court action which can be carried out by parties to a case. A large proportion of this body of law is descriptive and factual, but complex too; and the constraints of academic curricula do not allow students to learn procedural law in the real environment of the court. As a result, even with the inclusion of case law, and with examples to contextualize the procedural principles, the subject can be perceived as an exercise in knowledge acquisition alone (Vaughn, 1995).

This was the case with the Civil and Criminal Procedure module offered by the department of Law and Public Administration at Glasgow Caledonian University. In the original framework for teaching and assessment within the module, we attempted to address these issues in the syllabus by asking students to draft documentation from either side of the court action using precognitions (statement of the client) issued to them, and to integrate this with aspects of procedure. They also produced a letter to a client dealing with a problem which would require them to address procedural issues. This project was, in effect, a limited practical application of what they were learning in their lectures and tutorials. 
However, there were drawbacks to this approach. Interactivity was minimal, and there was no place in it for the role of the Sheriff Clerk (the court administrator). This absence changed the process significantly, and may have confused students. In addition, students were not involved in legal decision-making processes, and were working in a vacuum with little sense of the pressures of a court action and responsibilities owed to the client. The idea of transforming this approach to a more active-learning one - one in which students would raise and defend their own hypothetical actions - was attractive, but within the confines of a paper-based environment this was impractical for a number of reasons:

1. The process of drafting becomes mechanistic with the student concentrating on format not content (Kissam, 1987).

2. The time required to complete the project would be disproportionate in relation to other subjects covered in the module.

3. There were practical difficulties in the transmission of documents between parties.

4. The member of staff who acted in the role of Sheriff Clerk would have to be available in person, during office hours, for the duration of the project. This would have been an inefficient use of staff time

5. There was no opportunity for tutor involvement, and tutors could only with difficulty monitor student progress.

6. Student progression from one document to another could not be checked.

The Virtual Court Action was developed by the authors of this paper in late 1996 to address these and other issues.

\section{Development of the software}

From the start we defined a number of approaches we wished to take in the design of the software. The Law department had identified a set of personal transferable skills (PTSs) we wished students to develop. A number of these, particularly group work, problem-solving and communication skills, were targeted in our design. ${ }^{1}$ Our department had also taken a policy decision to develop computer-based learning (CBL) using constructivist principles where possible. This included the use of simulations and context-rich situated learning what Grabinger and Dunlap (1995) have termed REALs: Rich Environments for Active Learning. In addition, we wanted to use CBL to promote problem-solving and higher-level critical skills within the domain of legal procedure (Facione, 1986; McMillan, 1987).

However, we were aware that what might be termed a radical constructivist intervention in the curriculum, in which students would be plunged into problem-solving without many of the usual support mechanisms, may well have had the effect of de-motivating students (Laurillard, 1993). We therefore decided to adopt an approach which drew upon the rhetorical tradition of imitatio, which was redeployed recently in the cognitive approaches to learning by, among others, Pirolli and Anderson (1985). They observed that examples play an important role for students in the learning of concepts. This principle was taken further by Kessler and Anderson (1986), who suggested that effective learning in the field of computer programming is enhanced through the development of meta-skills where learners learn to construct mental models of examples which can then be transferred to 
other, related tasks. In our developmental work we applied this methodology to the field of legal procedure and document-drafting in order to facilitate students in the acquisition of these skills. In taking this approach to task design, we were attempting to achieve a balanced constructivist view of learning which would enhance critical thinking and PTSs.

The Virtual Court Action was constructed using HotDocs, an intelligent document assembly application. HotDocs interfaces with a number of standard word-processing programs, in our case MS Word 6. We chose this word processor for several reasons:

1. It enabled us to create context-rich environments because it provided us with an environment in which to design and create complex templates.

2. Having learned to use Word in IT modules, our students would readily grasp the HotDocs interface.

3. The application is widely used by legal firms in the USA, and a number of legal firms in the UK were already using it.

To begin the process of authoring templates, we identified text variables within documents, and linked these variables to user prompts and help text. We then created and customized a user-interface by grouping variables into dialogues, providing help text where appropriate.

Throughout, we were concerned to strike the balances between what we regarded as pairs of unproductive extremes. The first pair concerned giving support in problem-recognition. We needed to give students the right sort of information to make them aware that a decision had to be made, without leading them overtly through the process. If they simply filled in variables without understanding the procedural logic underlying their choices, they would come to very little understanding of the process of legal procedure; nor would they be practising any PTSs. In this, we wanted to avoid the situation described by Atkins (1993) who suggested that the constructivist use of interactive technologies and simulations tend to rely on pre-determined decision points, and that it may be difficult 'to improve users' interpersonal skills in professional contexts where the user would himself be an important factor in the way the situation developed'.

The second of these pairs involved providing enough information to support student problem-solution, and supplying too much. If too little information about the nature of the task were provided, students would be unable to transfer their learning from lectures and tutorials. But if too much information were available, navigation through windows of text could become difficult for users. In addition, there would be little in the way of problemsolving for students to carry out.

In striking these balances, it was crucial for us as developers to see tasks from the users' point of view, and to distinguish between cognitively simple and cognitively complex tasks. Simple tasks could be performed for the users by the software. Complex tasks were those nodal or crucial tasks, in the performance of which students would need to consider document format, content, audience, procedural alternatives, timelines, or any combination of these. Clearly, the cognitive complexity of any task increased as the number of the above factors in it increased, and we were aware that if the software were to be successful, the level of task complexity would have to be carefully planned.

For this reason, we designed help text at key points in the dialogues to provide a support 
scaffold for students' decisions. We hoped this scaffold would alert students to the necessity to make a decision, without telling them which decision it was, or the appropriate solution. More particularly, the scaffold allowed us space in which to define terms, explain aspects of procedure, guide students' strategic choices, and alert students as to the consequences of specific decisions.

\section{Description of the software use}

The project was piloted over a four-week period in February 1997 with 70 full-time and part-time undergraduates. The students were assigned to groups of three, and each group became the pursuer or defender in a civil court action. The role of the Sheriff Clerk was taken by the course tutor. Each side was issued with a unique case scenario which gave sufficient information to allow the action to be initiated or defended. The students then actively progressed the action by drafting the appropriate legal documentation and corresponding with each other and with the Sheriff Clerk using email. During the process, students responded to the various dialogues and prompts presented to them. These responses were merged with the template to produce the final formatted document. Time limits were based on those set by the court, taking account of the University semester.

At the conclusion of the project, the students were required to submit, inter alia,

- a portfolio for assessment which included a printed copy of all documentation pertaining to their case;

- an individual report which identified and summarized the learning objectives and skills that had been met as a result of participating in the project

The library of document templates was made available to all students. Each group then had to identify the appropriate documentation for their roles as either pursuer or defender. Next, they needed to assemble the document electronically by answering questions presented in the dialogues. These dialogues supported user-needs to understand all the relevant legal points arising from the document, and the communicational variables within the document. Both pursuers and defenders would thus find all the supporting information they needed within the dialogues and the help facility.

A series of different dialogue types was employed in each document template in order to provide a rich and appropriate learning environment. These ranged from simple selection from a list of given options to drafting sections of text incorporating legal argument. The resulting document was then sent to the appropriate party by email. The action continued as in the actual court environment with the parties corresponding with each other and the Sheriff Clerk. A distinct advantage of the Virtual Court Action over the paper-based version was access to the Sheriff Clerk, which was considerably improved through the use of email. In addition, where in a paper-based project the Sheriff Clerk would have assumed a passive and reactive role only, in the virtual version the tutor/Sheriff Clerk was able to monitor student progress and interact with students where appropriate. This interaction is important in realia scenaria - take, for example, Jones $(1994,182)$ : 'Feedback [on a task] should be [. . .] immediate and students should also be able to move on as and when they wish'.

The students received a one-hour training session prior to the commencement of the project, and were provided with user-guides for the Virtual Court Action and email. 
Student feedback from questionnaires showed that this was adequate preparation $(85$ per cent indicated they could use email effectively, and 90 per cent that the dialogues were straightforward to complete.)

\section{Project evaluation methodology}

Much of our project evaluation methodology derives from the recommendations of the TILT Project (Draper et al, 1995). In particular, we were aware that our evaluation, because it was integrated with real-time teaching and learning and therefore open to autocompensation and many other effects, would not be a controlled experiment but an evaluation of the overall teaching and learning situation. We were satisfied that as such, it would be 'ecologically valid' for its purposes (Draper et al, 1995).

The real-time nature of our evaluation meant that direct comparison between a paper-based version and a virtual version of the project within the same year group was impracticable from an administrative point of view, and might also possibly be construed by students as inequitable from an assessment point of view. We did, however, elicit qualitative data on the advantages and disadvantages of the learning method as it existed previous to The Virtual Court Action. Students were of the opinion that this method was 'a bit artificial', and could give rise to confusion about roles and procedures. Neither of these criticisms was made of The Virtual Court Action. Indeed, it was significant that students from the previous year who took part in the video protocol indicated that the application made the creation of documents 'more straightforward' and allowed them to 'concentrate on what was in the document rather than the format of it' (evaluation action research notes).

Formative evaluation was employed during development of the templates and userinterfaces in order to determine the ease of navigation within and between templates. This took the form of video talk-aloud protocols which were used with groups of students. After studying their responses and comments, a number of aspects of the user interface were modified.

In the summative evaluation, students were asked to provide feedback in the form of a questionnaire as well as in the report which was submitted for assessment. The aim of the questionnaire was, firstly, to assess the success of the project in terms of student motivation and perception of skills/knowledge acquired, and secondly to provide feedback for future development. Throughout the period of the project the groups were also observed informally in the computer laboratories.

\section{Discussion of student feedback}

Of the 70 students who took part in the project, 52 ( 74 per cent) completed and returned the questionnaire. The following analysis of feedback has been restricted to that part of the questionnaire which focuses on the students' perception of the usefulness of the project and the evaluation of confidence levels among the students using the software.

Feedback from the students has been very positive. A summary of the most significant results is detailed in Figure 1.

All of the students found the courseware useful, with 83 per cent expressing a positive benefit from participating, and a significant majority ( 65 per cent) indicating that they 

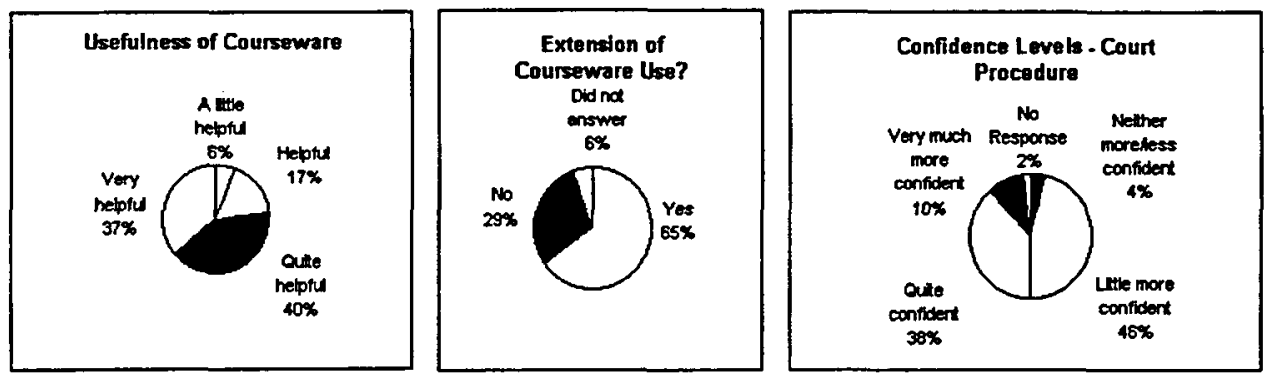

Figure I: Summary of student-feedback results

would like to see the courseware extended within the module. An encouraging 94 per cent stated that their confidence level in procedure had increased. Similarly, 83 per cent indicated their confidence levels in document-drafting had increased. In neither case. were students less confident. While confidence should not be equated with competence, it is axiomatic that confidence can be regarded as an indicator of how an individual expects to perform in a given situation.

One aim in developing this courseware was to shift the emphasis from traditional lectures and seminars in order to make more effective use of staff time. Although 39 per cent of students indicated that they would accept a reduction in the number of seminars and lectures, only 8 per cent were in favour of total replacement. This is possibly a reflection of students' unwillingness to relinquish the traditional forms of learning. It should be noted that during the pilot project one seminar per week was dropped compared to previous years, and the intention is to increase this in future.

Students comments contained in the questionnaires and reports were extremely positive. Comments fell into three categories: active learning, acquisition of PTS, and vocational relevance. Students liked the interactivity of the program ('[it] made us recognize the procedure because we were part of it rather than being told about it during a lecture'). Although the acquisition of PTSs was not formally addressed with students, it is clear from the comments that students were able to identify and acquire a range of PTSs they practised in the project. They recognized that they were working in groups and individually, meeting time limits, and enhancing their communication and learning skills. As one student put it, '[it was a] worthwhile exercise, promoting a joint learning experience encouraging teamwork and individual participation and responsibilities'. Students found the vocational relevance of the project stimulating, with comments like: 'This is more relevant to what happens in the workplace when targets have to be met'. Moreover, students very strongly indicated further improvement of their general IT skills, in particular the practical application of email and document assembly.

\section{Future directions}

As a result of the success of this pilot, we intend to:

- increase software use within the area of civil procedure and other court processes within the module, and apply it to other areas of substantive law; 
- incorporate other innovative applications of IT to provide further enhancements to the project - the most significant of these is the creation of a discussion forum such as an Answer Garden (Ackerman and Malone, 1990), allowing students to exchange ideas and participate in peer learning;

- investigate distance-learning options and real-time conferencing applications.

\section{Conclusions}

Students clearly enjoyed taking part in the project. This resulted in increased motivation not only to complete their tasks but also to understand civil court procedure. The real-life environment and contextualization of the subject material was a positive incentive for students, allowing them to set their own objectives and see the effect of their own actions. Overall, the quality of submitted work improved. In particular the summative assessment revealed a higher level of understanding of the interactive nature of the court process.

\section{Note}

1 The legal profession supports the view that PTSs should be embedded at undergraduate level. In a survey of solicitors discussing the content of the legal curriculum in England and Wales, for instance, respondents were of the opinion that Law graduates did not possess sufficient problem-solving or communicational skills, and that these should begin to be taught at the academic stage of legal education (Bright, 1991)

\section{Acknowledgements}

The authors would like to thank Dr Paul Maharg of the Department of Law and Public Administration, Glasgow Caledonian University, for his invaluable help and encouragement.

\section{References}

Ackerman, M. and Malone, T. (1990), 'Answer Garden: a tool for growing organisational memory', Proceedings of the Conference on Office Information Systems, New York: ACM Press.

Atkins, M. J. (1993),' 'Evaluating interactive technologies for learning', Journal of Curriculum Studies, 25 (4), 333-42.

Bright, S. (1991), 'What and how should we be teaching?', The Law Teacher, 25 (1), 11-25.

Draper, S. W., Brown M. I., Henderson, F. P. and McAteer, E. (1995), 'Integrative evaluation: an emerging role for classroom studies of CAL', http://www.psy.gla.ac.uk/ $\sim$ steve/IE.html\#Auto

Facione, P. A. (1986), 'Testing college-level critical thinking', Liberal Education, 72, 221-31.

Grabinger, R. S. and Dunlap, J. C. (1995), 'Rich Environments for Active Learning: a definition', $A L T-J, 3$ (2), 5-34.

Jones, R. (1994), 'Computer-managed teaching and learning in Law', International Yearbook of Law, Computers and Technology, volume 8, 173-83. 
Kessler, C. M. and Anderson, J. R. (1986), 'Learning flow of control: recursive and iterative procedures', Human-Computer Interaction, 2, 135-66.

Kisșam, P. C. (1987), 'Thinking (by writing) about legal writing', Vanderbilt Law Review, 40, 135-73.

Laurillard, D. (1993), Re-thinking University Teaching, London: Routledge.

McMillan, J. H. (1987), 'Enhancing college student's critical thinking: a review of studies', Research in Higher Education, 26, 3-26.

Pirolli, P. L. and Anderson, J. R., (1985), 'The role of learning from examples in the acquisition of recursive programming skills', Canadian Journal of Psychology, 39 (2), 240-72.

Vaughn, R. G. (1995), 'Use of simulations in a first-year civil procedure class', Journal of Legal Education, 45, 480-6. 